\title{
ARTIGO
}

\section{ESTRATÉGIAS DE APRENDIZAGEM E CURSOS DE EDUCAÇÃO A DISTÂNCIA: SATISFAÇÃO DOS ALUNOS MATRICULADOS E EGRESSOS EM CURSOS PROFISSIONAIS ${ }^{1}$}

\author{
Ronielton Rezende Oliveira ${ }^{2}$ \\ Luiz Antônio Antunes Teixeira \\ Maria Edilene do Amaral Silva Santos
}

\begin{abstract}
RESUMO
As instituições de ensino superior necessitam compreender a percepção dos seus alunos para efetivamente estabelecer ações de gestão acadêmica. Este estudo apresenta o efeito da estratégia de aprendizagem na satisfação com o curso dos alunos matriculados e egressos do Centro de Educação Aberta e a Distância do Campus Ouro Preto do Instituto Federal Minas Gerais. A estratégia metacognitiva e estratégia autorregulatória constituem os antecedentes da estratégia de aprendizagem. A análise de dados utilizou a estatística multivariada por meio da Modelagem de Equações Estruturais com estimação por Mínimos Quadrados Parciais. Os resultados apontam que os alunos egressos inseridos no mercado de trabalho na área de conhecimento do curso que realizaram, percebem com mais clareza a importância da capacitação e educação na sua vida profissional. A estratégia metacognitiva é a que se destaca, ao ser aquela que conduz o aluno a refletir sobre o seu próprio pensamento para realizar uma atividade com sucesso e alcançar seu objetivo de aprendizado.
\end{abstract}

Palavras-chave: Educação. Metacognição. Autorregulação. Análise Multi-grupo. PLS-MGA.

\section{INTRODUÇÃO}

A educação no Brasil está organizada em dois níveis: educação básica (infantil, fundamental e médio) e educação superior. Além das próprias modalidades de ensino que complementam o processo de educação formal, isto é, a educação de jovens e adultos, a educação profissional, a educação especial, o ensino presencial, o ensino semipresencial, a educação continuada e a educação à distância (SOARES, 2002). Essa última vem ganhando

\footnotetext{
${ }^{1}$ Como citar este artigo: OLIVEIRA, Ronielton Rezende; TEIXEIRA, Luiz Antônio Antunes; SANTOS, Maria Edilene do Amaral Silva. Estratégias de aprendizagem e cursos de educação a distância: satisfação dos alunos matriculados e egressos nos cursos profissionais. ForScience: revista científica do IFMG, Formiga, v. 7, n. 2, e00615, jul./dez. 2019. DOI: 10.29069/forscience.2019v7n2.e615.
}

\footnotetext{
${ }^{2}$ Autor para correspondência: Ronielton Rezende Oliveira, e-mail: ronielton@ fumec.edu.br.
} 
espaço e se destacando no Sistema de Ensino Brasileiro. No aspecto prático, a constatação é que as Instituições de Ensino Superior (IES) perceberam a oportunidade de ampliar suas fronteiras, oferecendo cursos que possibilitam o ingresso de alunos de qualquer região do País (MIRANDA; TONINI, 2013) e com isso, fomenta-se a educação e busca-se uma melhor aplicação das políticas públicas que envolvem o treinamento formal da população.

Os processos de gestão educacional são complexos (AROSTI; DUMBRA, 2014; CHAVES et al., 2014;) e a "administração educacional não se dá no vazio, mas em condições históricas determinadas, que expressam as contradições sociais e a correlação de forças existentes na sociedade, podendo contribuir tanto para a conservação, como para a transformação social" (CHAVES et al., 2014, p. 5). A escola pode ser entendida como uma instituição social, que não somente é constituinte, mas, constitutiva da sociedade em que se encontra inserida. As IES e seus administradores necessitam aprimorar as maneiras de gestão e isto significa encontrar estratégias que favoreçam o alcance dos resultados. Todavia, nos estudos organizacionais o conceito de estratégia é difundido nas mais variadas formas e significados no campo da administração. O fato é que não existe uma definição única e definitiva para estratégia. Essa pode representar "desde um curso de ação formulado de maneira precisa, todo o posicionamento em seu ambiente, até toda a alma, a personalidade e a razão existencial de uma organização" (OLIVEIRA; GONÇALVES; MARTINS, 2017, p. 255).

Nota-se que desde a década de 1980, o uso das estratégias de aprendizagem vem sendo objeto de interesse entre os pesquisadores na área da educação. Contudo, foi a partir da década de 1990 que os instrumentos para mensurar tais estratégias foram construídos (SCACCHETTI; OLIVEIRA; MOREIRA, 2015). Essas estratégias são ações mentais e atitudes comportamentais que ajudam o aluno no processo de aprender a aprender, pois, as estratégias de aprendizagem são instrumentos de autorregulação do aluno que contribuem para que ele coloque seu processo de aprendizagem em funcionamento (CASTRO; MIRANDA; LEAL, 2016). No mais, com o uso das estratégias é possível que com o intuito de que a aprendizagem ocorra, o aluno consolide o conhecimento a ser construído, armazenado e recuperado nas condições de avaliação acadêmica ou mesmo, durante o exercício da profissão.

O aluno organizado conduz seu processo de aprendizagem de forma responsável em relação aos objetivos que quer alcançar, logo, ao ser autorregulado está consciente da necessidade de ser ativo para que a aprendizagem aconteça (GALVÃO; CÂMARA; 
JORDÃO, 2013; CASTRO; MIRANDA; LEAL, 2016). Sendo assim, ao administrar seus esforços e habilidades para construir o próprio conhecimento, o aluno utiliza-se da metacognição, isto é, aprender a aprender (KOCH, 2011; GALVÃO; CÂMARA; JORDÃO, 2013). Portanto, autorregulação e metacognição andam juntas e a adoção de estratégias de aprendizagem facilita o nível de desenvolvimento e por consequência, o aluno se torna motivado a aprender (CROTI, 2016). Tão importante quanto identificar as estratégias de aprendizagem, é avaliar o grau de satisfação dos alunos com o curso, uma vez que alunos contentes são leais e voltam quando necessitam obter novos conhecimentos, além de que também recomendam à IES a outras pessoas de seu círculo de relacionamentos (MURITIBA; ALBUQUERQUE; MOURA, 2012).

O estudo se sustenta sobre a questão de pesquisa: qual a relação entre as estratégias de aprendizagem (metacognitiva e autorregulatória) e a satisfação com o curso na modalidade de educação profissional à distância? Dessa forma, o objetivo é analisar as relações das estratégias de aprendizagem na satisfação com o curso na modalidade de educação profissional a distância dos alunos matriculados e egressos do Centro de Educação Aberta e a Distância (CEAD) do Instituto Federal de Educação, Ciência e Tecnologia de Minas Gerais (IFMG) - Campus Ouro Preto em específico, no nível técnico.

\section{ENSINO PROFISSIONAL, EDUCAÇÃO A DISTÂNCIA E SATISFAÇÃo COM O CURSO}

O ensino profissional no Brasil refere-se à implantação dessa modalidade no nível médio, com a Lei n. 5.692 de 11/08/1971. Na sua origem a educação profissional procurava disciplinar o trabalhador para atuar no sistema capitalista, em que havia dominante e dominado, pois, mais do que formar um profissional para atender as indústrias, pretendia-se que fosse garantido o poder da elite (FALCIONI; AMORIM, 2009). Nos dias atuais, é por meio do ensino profissional que as pessoas buscam por capacitação e qualificação com a intenção de gerar um diferencial de renda e aumentar sua probabilidade de inserção no mercado de trabalho (GÓES; ALLIPRANDINI, 2014; VALE; OLIVEIRA; SOUSA, 2016; SANTOS, 2017).

A aprovação da Lei n. 9.394 de 20/12/1996 (Diretrizes e Bases da Educação - LDB) e o Decreto n. 5.622 de 19/12/2005 foram fundamentais para a Educação a Distância (EaD) no Brasil. A LDB em seu art. 80 trata a educação a distância de modo amplo, mas, é o Decreto que aborda detalhadamente os aspectos dessa modalidade de ensino. A verificação é que mais 
recentemente, com o intuito de debater as políticas sociais para redução da pobreza e da desigualdade, a educação profissional passou a ser abordada nas pesquisas (SEVERINI; ORELLANO, 2010; SANTOS; CARDOSO; BORGES, 2014; PACHECO; MESQUITA; DIAS, 2015; CROTI, 2016). Esses estudos demonstram que a modalidade EaD é uma maneira das IES realizarem uma prática pedagógica singular, a qual resulta em uma nova oportunidade de aprendizagem, precisamente, quando os discentes se apropriam do conhecimento mediado pelo uso da tecnologia (SANTOS; CARDOSO; BORGES, 2014; SILVA et al., 2015).

A educação a distância possibilita uma "transformação social num determinado tempo e espaço histórico" (FARIAS; LOPES, 2014, p. 19), pois é práxis social em que os sujeitos fazem acontecer o processo de ensino apoiados em recursos tecnológicos pelos quais estabelecem um canal de comunicação, seja entre si com a troca de informações, seja na relação mestre e aprendiz. Inclusive, é com a interatividade proporcionada pela internet que a modalidade EaD permite obter a qualificação profissional de forma virtual, ao garantir que os alunos desenvolvam às aptidões necessárias para atuarem num mercado de trabalho competitivo (FORTES; HAACK, 2013). Por isso, a qualidade e a intensidade dessa interatividade são fundamentais para o sucesso da educação a distância (AFFONSO; QUINELATO, 2014; SANTOS; CARDOSO; BORGES, 2014), além de que a satisfação é essencial para que o aluno se sinta motivado ao longo de sua trajetória acadêmica (VIEIRA; MILACH; HUPPES, 2008; MAINARDES; DOMINGUES, 2010; PACHECO; MESQUITA; DIAS, 2015).

A palavra satisfação remete à ideia de alguma coisa que se pretende ter ou a realização de algo que se almeja conquistar, ao ter uma ligação direta com a perda de uma necessidade ordenada pela expectativa em relação a um produto que se deseja consumir, avaliar ou adquirir (SOUZA; REINERT, 2010). Essa ideia de satisfação, mesmo que pertencente à área de marketing, por se tratar de satisfação do cliente, é oportuna para uma reflexão sobre a satisfação de alunos com um determinado curso de que pretendem participar (PACHECO; MESQUITA; DIAS, 2015). Porque, na área de educação as consequências da satisfação estão relacionadas à lealdade, ao lucro nas IES privadas, as parcerias discente e docente que levam produtividade acadêmica nas IES públicas e à realização de outros cursos por parte dos alunos egressos, pois eles tendem a voltar à IES, recomendá-la ao seu ciclo de amizade e também podem contribuir com doações de recursos, por exemplo, ao criarem associações de ex-alunos 
(MURITIBA; ALBUQUERQUE; MOURA, 2012; GOUVÊA; ONUSIC; MANTOVANI, 2016).

Quando existe uma boa interação entre o aluno e a IES, o primeiro tem suas necessidades e interesses atendidos pelo segundo e isso, resulta na aprendizagem e em satisfação (SCACCHETTI; OLIVEIRA; RUFINI, 2014). A satisfação acadêmica consiste da avaliação subjetiva da experiência pessoal associada à educação, sendo definida como "um estado psicológico resultante da confirmação, ou não, das expectativas do estudante com a realidade acadêmica" (RAMOS et al., 2015, p. 188). A satisfação com o curso, portanto, é o estado psicológico resultante da confirmação ou desconfirmação das expectativas do aluno com o contexto acadêmico em função da estratégia de aprendizagem e seus antecedentes adotados pelos discentes, a saber, estratégia metacognitiva e estratégia autorregulatória (MURITIBA; ALBUQUERQUE; MOURA, 2012; SCACCHETTI; OLIVEIRA; RUFINI, 2014; PACHECO; MESQUITA; DIAS, 2015; RAMOS et al., 2015; GOUVÊA; ONUSIC; MANTOVANI, 2016).

\section{ESTRATÉGIA METACOGNITIVA}

O termo metacognição tem origem na psicologia e se refere à capacidade que o aluno desenvolve para refletir sobre seus processos cognitivos ao ter controle sobre eles. A "metacognição não é somente o ato de pensar, mas a capacidade de pensar sobre o próprio pensamento, ou, ainda mais, o ato de avaliar o pensar sobre os nossos pensamentos" (LIMA FILHO; BRUNI, 2015, p. 429). Isso significa que a metacognição é o processo de aprender a aprender, isto é, construir o próprio conhecimento (KOCH, 2011; DANTAS; RODRIGUES, 2013), potencializando-o e conscientizando-se acerca do que o aluno conhece e do que desconhece sobre o seu aprendizado (LIMA FILHO; BRUNI, 2015), sendo o conhecimento, então, alcançado sobre os próprios processos mentais do indivíduo (CROTI, 2016).

A estratégia metacognitiva é um procedimento intrínseco que o aluno adota para planejar, monitorar e regular o próprio pensamento diante de uma tarefa acadêmica. Seu uso manifesta-se: a) no planejamento, que abrange o estabelecimento de objetivos para o estudo e as metas a serem cumpridas; b) no monitoramento, que é o responsável pela conscientização do seu desempenho e da própria atenção; e c) na regulação, que permite que o comportamento de estudo seja modificado durante a realização da tarefa (OLIVEIRA; BORUCHOVITCH; 
SANTOS, 2009; CORSO et al., 2013; GÓES; PAVESI; ALLIPRANDINI, 2013; PERASSINOTO; BORUCHOVITCH; BZUNECK, 2013; GÓES; ALLIPRANDINI, 2014).

Administrar o tempo, organizar o ambiente de estudo e pedir ajuda também podem ser considerados exemplos de estratégia metacognitiva. Em outras palavras, esse tipo de estratégia representa a consciência mental que é utilizada para aprender e a capacidade de reconhecer as formas utilizadas para que uma aprendizagem duradoura aconteça (ALLIPRANDINI et al., 2014). A estratégia metacognitiva, portanto, é a consciência dos processos mentais utilizada na aprendizagem, que leva o aluno a refletir sobre seu pensamento em relação a satisfação com o curso (OLIVEIRA; BORUCHOVITCH; SANTOS, 2009; KOCH, 2011; PERASSINOTO; BORUCHOVITCH; BZUNECK, 2013; CORSO et al., 2013; GÓES; PAVESI; ALLIPRANDINI, 2013; LIMA FILHO; BRUNI, 2015; SANTOS, 2017). Isso sugere a hipótese H1, na qual a estratégia metacognitiva exerce um efeito positivo na satisfação com o curso.

\section{ESTRATÉGIA AUTORREGULATÓRIA}

Para compreender o processo de aprendizagem é preciso perceber que a motivação é um processo iniciado por um motivo que leva qualquer sujeito a realizar algo de forma voluntária. Após a escolha, "este impulso permanecerá, mantendo o sujeito no processo até que atinja os objetivos traçados naquilo que se propôs a fazer" (ISLER; MACHADO, 2013, p. 70). Todavia, o processo motivacional varia de intensidade de acordo com a atividade e com as pessoas. Desse modo, a "autoregulação da motivação é descrita como o grau em que os indivíduos agem de forma intencional, no sentido de iniciar, manter ou reforçar sua determinação em se envolver e completar uma tarefa ou atingir um objetivo" (PAULINO; SILVA, 2012, p. 101).

Os alunos se sentem mais motivados a aprender quando percebem que o uso de determinadas estratégias facilita o seu desenvolvimento acadêmico (CROTI, 2016). A estratégia de aprendizagem se torna um instrumento de autorregulação, ao passo que ajuda o aluno a aprender a aprender e a ter o comando sobre o seu processo de aprendizagem (DANTAS; RODRIGUES, 2013; CASTRO; MIRANDA; LEAL, 2016). Aprender a aprender, então implica na autonomia e responsabilidade com o ato de estudar e ainda, regular e planejar as tarefas acadêmicas, refletindo sobre as ações já realizadas e escolhendo as 
melhores e mais adequadas formas para que a aprendizagem ocorra (FERNANDES; FRISON, 2015).

Não basta conhecer as estratégias para melhorar o aprendizado. É preciso compreender como e quando utilizar tais estratégias. Sublinhar pontos importantes de um texto, usar técnicas de memorização, fazer resumos, dentre outras formas, são bons exemplos de medidas autorregulatórias que podem ajudar no bom desempenho do aluno (BORUCHOVITCH, 1999). A estratégia autorregulatória, portanto, é o aprender a aprender e ter controle sobre o processo de aprendizagem, quando conduz o aluno a regular a si mesmo em relação a satisfação com o curso (PAULINO; SILVA, 2012; ISLER; MACHADO, 2013; FERNANDES; FRISON, 2015; CASTRO; MIRANDA; LEAL, 2016; CROTI, 2016; SANTOS, 2017). Isso sugere a hipótese H2, na qual a estratégia autorregulatória exerce um efeito positivo na satisfação com o curso.

\section{ESTRATÉGIA DE APRENDIZAGEM}

A estratégia metacognitiva e a estratégia autorregulatória estão interligadas e possibilitam que o aluno atue sobre suas ideias e controle sua aprendizagem (CROTI, 2016). Elas são indissociáveis e se entrelaçam quando o aluno age em busca de aquietar um questionamento, regulando seus pensamentos, monitorando sua própria aprendizagem e tornando-se motivado a aprender. Com isso, tem-se a estratégia de aprendizagem a partir do momento em que o aluno, como aprendiz, compreende que seu uso favorece o nível de desenvolvimento intelectual e consequentemente, o leva a se sentir satisfeito (UMEKAWA; ZERBINI, 2015; CROTI, 2016).

Os alunos quando submetidos a ambientes tecnológicos são marcados por desafios emocionais, motivacionais, cognitivos e colaborativos que exigem controle de seus esforços para gerenciar sua aprendizagem, impondo a busca de estratégias que se diferenciam das formas tradicionais (SALOVAARA, 2005). Para alcançar a aprendizagem o aluno se vale de diferentes modos de aprender de acordo com a natureza e o grau de complexidade da atividade acadêmica (WARR; ALLAN, 1998; ZERBINI; ABBAD, 2008). Por isso, o aluno que organiza e conduz seu processo de aprendizagem de forma responsável em relação aos objetivos que quer alcançar, é um aluno que apresenta autorregulação. Ele é consciente da necessidade de ser ativo para que a aprendizagem aconteça. Administra seus esforços para o 
alcance dos conhecimentos e habilidades, utilizando-se, assim, da metacognição (CASTRO; MIRANDA; LEAL, 2016).

A estratégia de aprendizagem é o "comportamento desenvolvido pelo aluno com finalidade de facilitar a recuperação da memória de conhecimentos já adquiridos e, assim, otimizar a qualidade do aprendizado" (CASTRO; MIRANDA; LEAL, 2016, p. 82). A satisfação provém do contraste entre as expectativas prévias e a percepção atual. As pessoas criam expectativas acerca dos produtos ou serviços contratados e esta expectativa, se apresenta como uma superação ou negação (OLIVER, 1980; SILVA et al., 2015). O foco nesta pesquisa é analisar a satisfação com o curso profissional da modalidade EaD, portanto, por analogia, indica-se que a superação ou negação de expectativas dos alunos no processo de ensino pode ser estabelecida sobre a estratégia de aprendizagem e seu efeito na satisfação com o Curso.

Nesse sentido, a estratégia de aprendizagem é o conjunto de capacidades cognitivas complexas aprendidas pelos alunos ao longo da vida (OLIVER, 1980; ABBAD; CORREAA; MENESES, 2010; CASTRO; MIRANDA; LEAL, 2016; GOUVÊA; ONUSIC; MANTOVANI, 2016; SANTOS, 2017) e este estudo, avalia os efeitos das estratégias de aprendizagem (metacognitiva e autorregulatória) na satisfação com o curso da modalidade EaD. Isso sugere a hipótese $\mathbf{H 3}$, na qual a estratégia de aprendizagem tem um efeito positivo na satisfação com o curso. O modelo conceitual da pesquisa é exibido na Figura 1.

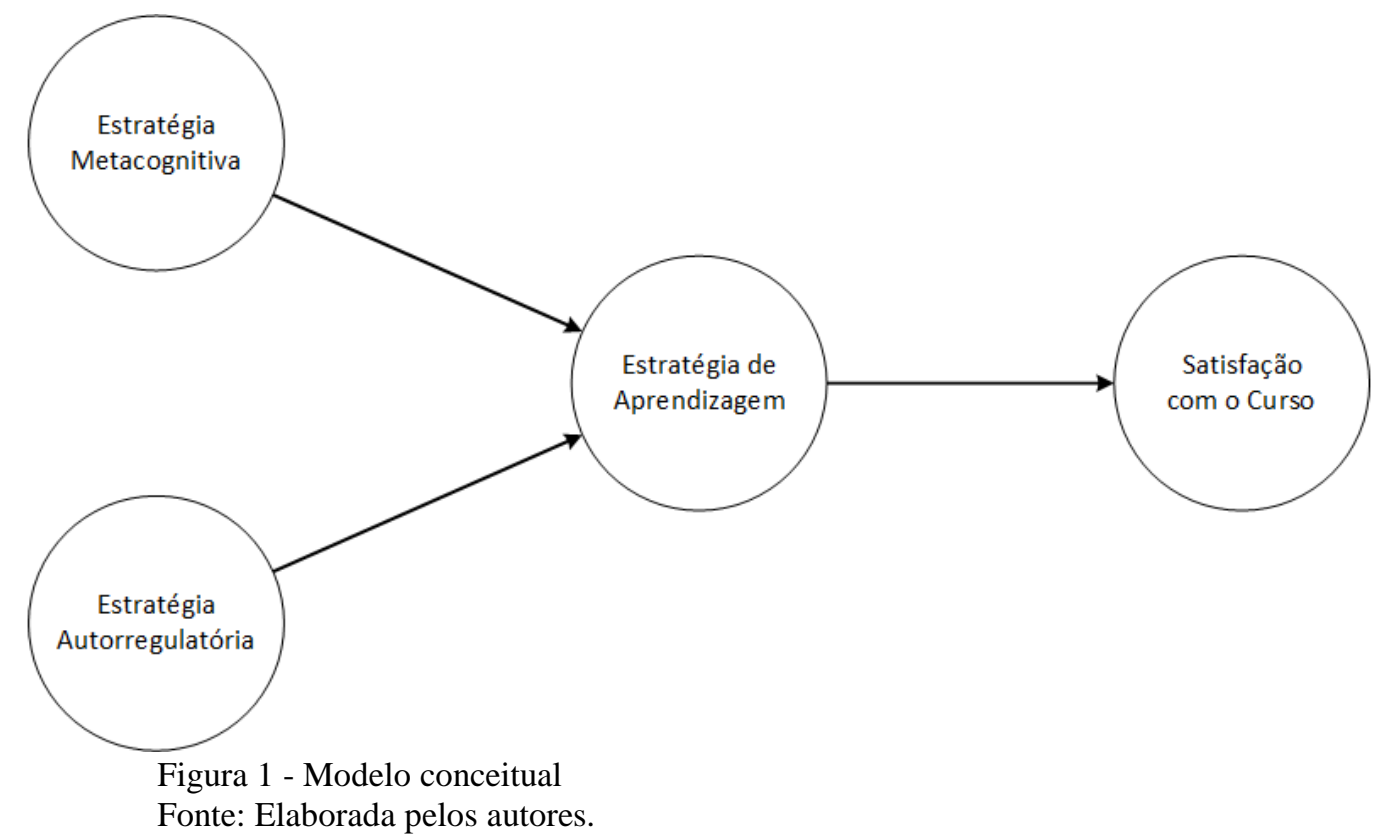




\section{METODOLOGIA}

O estudo de abordagem quantitativa e natureza descritiva foi realizado com alunos do CEAD/IFMG de cursos profissionais no nível técnico. O questionário utilizou escala Likert (discordo totalmente; discordo; não concordo nem discordo; concordo; concordo totalmente). A primeira parte foi formada por questões que identificam o curso de vinculação do aluno e as características relacionadas ao gênero, idade e atuação profissional associada a área do curso. A segunda parte com as questões base da pesquisa é apresentada no Quadro 1.

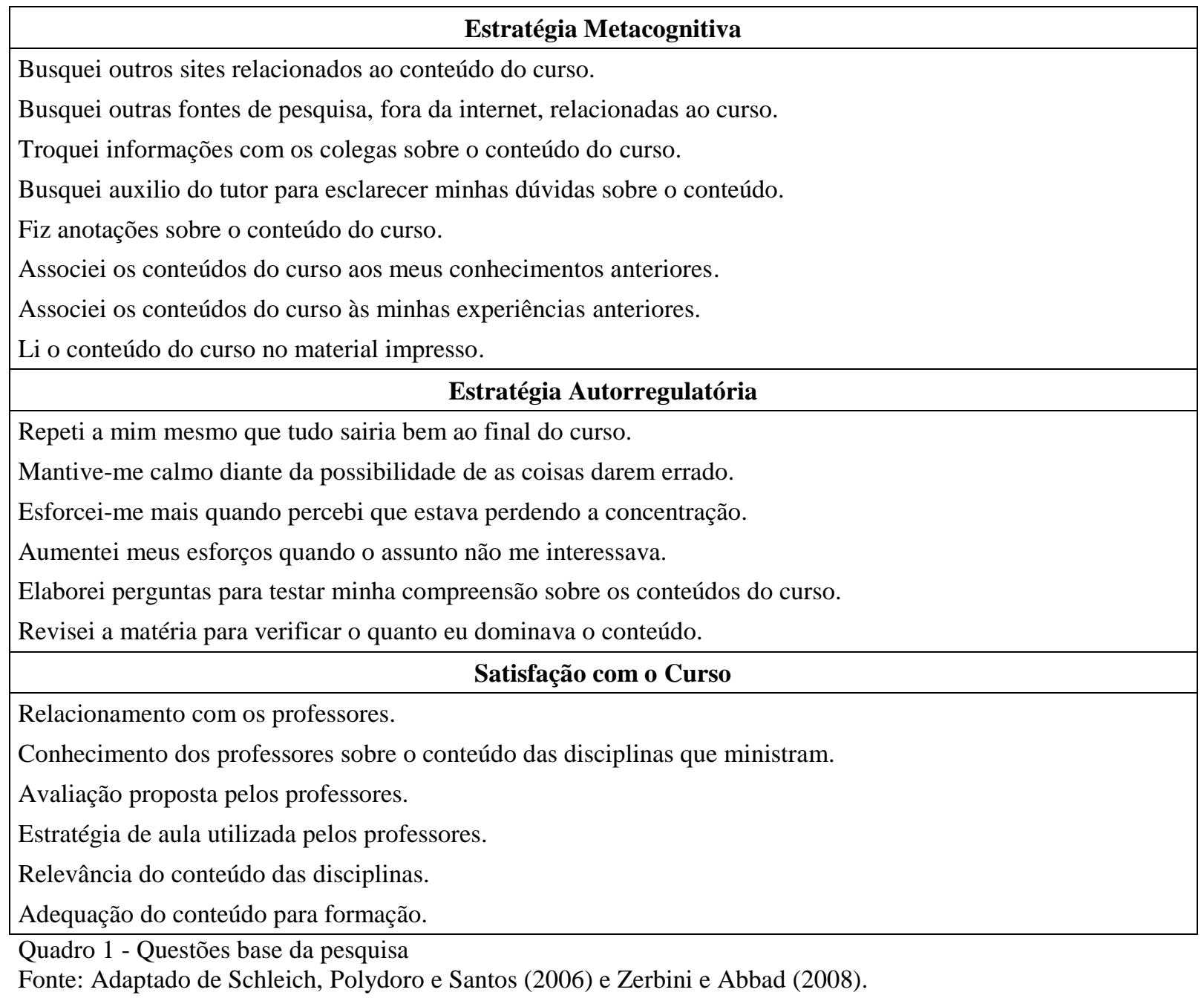

A coleta de dados foi efetuada pela aplicação presencial e exposição na internet do questionário. A amostra de 254 alunos é composta por 94 matriculados e 160 egressos. Uma questão nas pesquisas quantitativas é qual deve ser o tamanho da amostra. Para obter-se um poder estatístico de $80 \%$ o efeito sugerido é $f=0,15$ (COHEN, 1992). Neste estudo utilizou-se 
o software G*Power (FAUL et al., 2009). Os resultados que demonstram a adequação do tamanho da amostra em seus respectivos grupos são apresentados na Tabela 1.

Tabela 1 - Poder estatístico da amostra

\begin{tabular}{ccc}
\hline \multicolumn{3}{c}{ Descrição } \\
\hline \multicolumn{3}{c}{ Linear multiple regression: Fixed model, $\mathrm{R}^{2}$ increase } \\
\hline$f$-test & \multicolumn{1}{c}{ Nível de Significância } & Tamanho do Efeito Médio \\
\hline Tamanho da Amostra & 0,05 & 0,15 \\
\hline 254 & Grupo de Alunos & Poder Estatístico \\
94 & - & $100 \%$ \\
160 & Matriculados & $92 \%$ \\
\hline
\end{tabular}

Fonte: Elaborada pelos autores.

A análise dos dados ocorreu com uso da análise estatística multivariada. A Partial Least Squares Structural Equation Modeling (PLS-SEM) é adequada para efetuar a análise de relações entre um conjunto de variáveis independentes e mais de uma variável dependente, pois as variáveis latentes são estimadas como agregados lineares ou componentes que não apresentam restrições quanto às características de distribuição dos dados (LOHMÖLLER, 1988), ou seja, é um método não paramétrico que pode ser usado com dados não normais, especificamente, para verificar a plausibilidade de um modelo conceitual ao avaliar hipóteses de acordo com o fenômeno em investigação (OLIVEIRA; MARINHO; DIAS, 2016). Para testar simultaneamente múltiplos relacionamentos entre os construtos utilizou-se o software SmartPLS 3 (RINGLE; WENDE; BECKER, 2015; HAIR JR. et al., 2017).

\section{RESULTADOS E DISCUSSÃO}

As características demográficas dos respondentes indicam que $49 \%$ são do sexo masculino e $51 \%$ são do sexo feminino. Em relação à faixa etária, 2\% têm menos de 20 anos, $30 \%$ têm de 21 a 30 anos. A maior quantidade está na faixa de 31 a 40 anos, com 40\%; 18\% têm de 41 a 50 anos e, 10\% têm mais de 51 anos. Sobre o total de alunos por curso, verificouse que o curso de Serviços Públicos tem o maior número, com $28 \%$, seguido do curso de Controle Ambiental, com 25\%. Os cursos de Edificações e de Metalurgia mostram a mesma quantidade, com $12 \%$ cada. Esse também é o caso dos cursos de Automação Industrial e Hospedagem, com $7 \%$ cada. O curso de Eletroeletrônica tem $9 \%$. 
É importante estabelecer uma relação entre a situação acadêmica do aluno e a atuação profissional na área do curso. Ao segmentar a amostra em grupos, destaca-se que no caso dos alunos matriculados, $43 \%$ nunca trabalharam, 39\% trabalham na área do curso e 18\% trabalharam e não trabalham mais. No caso dos alunos egressos, $40 \%$ nunca trabalharam, $50 \%$ trabalham na área do curso e $10 \%$ trabalharam e não trabalham mais. A inserção dos grupos no mercado de trabalho em função da área do curso é apresentada na Figura 2.
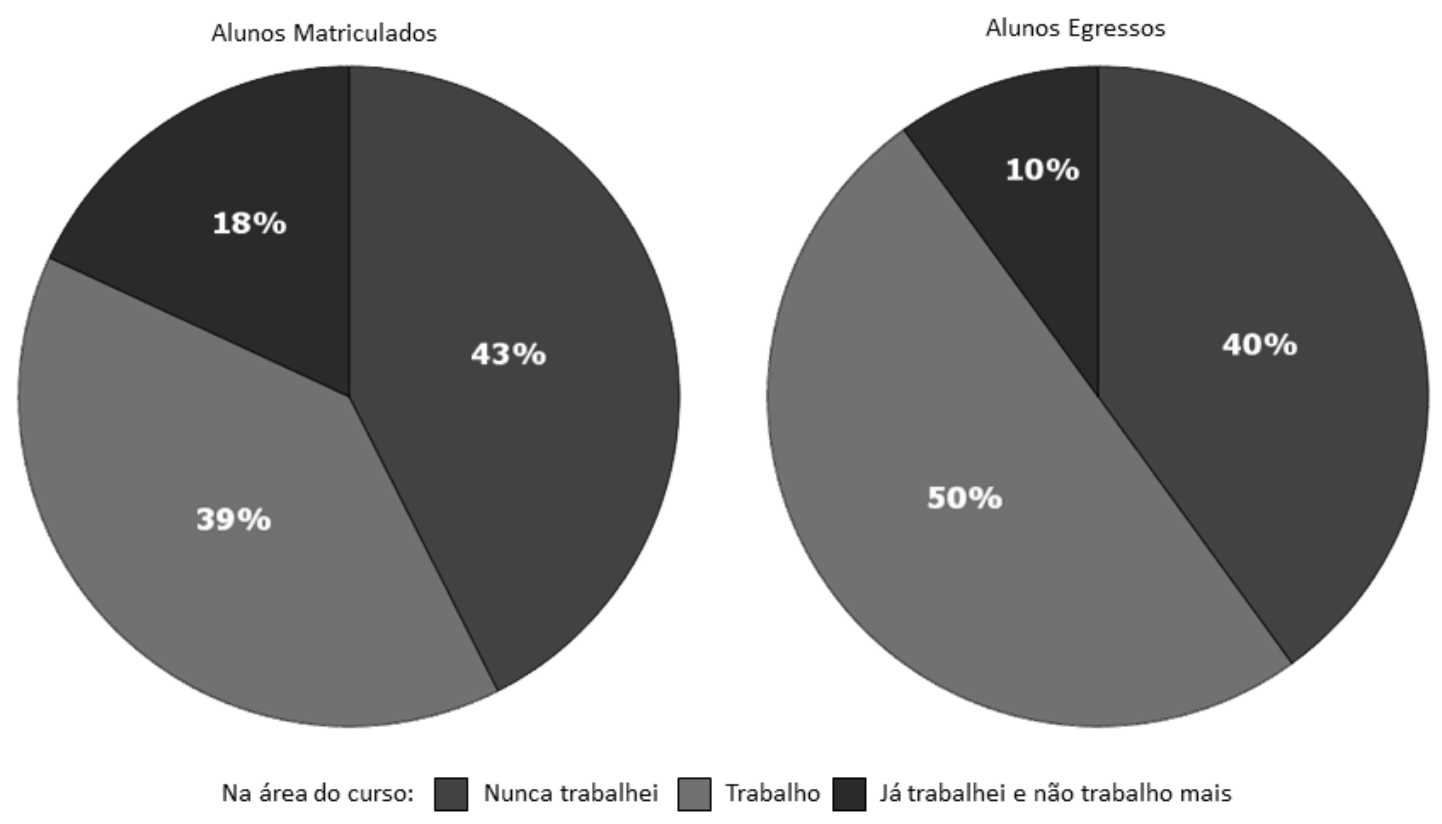

Figura 2 - Inserção dos grupos no mercado de trabalho Fonte: Dados da pesquisa.

A análise PLS-SEM segue duas fases que envolve avaliações do modelo de mensuração e do modelo estrutural (HAIR JR.; RINGLE; SARSTEDT, 2011). A primeira fase consiste em examinar a confiabilidade e a validade dos indicadores e construtos sobre a especificação do modelo de mensuração. A confiabilidade foi verificada pela análise do alfa de Cronbach e pela análise da confiabilidade composta e comprovou-se que os construtos possuem consistência interna. A validade convergente foi verificada pela análise de confiabilidade do indicador e pela verificação das cargas fatoriais com análise da variância média extraída (AVE). Confirmou-se a significância estatística das cargas externas de todos os indicadores, bem como um grau suficiente de AVE. A validade discriminante foi verificada utilizando-se o critério de Fornell-Larcker, para avaliar o nível do construto e a avaliação das cargas transversais, para avaliar o nível do indicador. Em ambos casos, as cargas fatoriais comprovaram que os construtos e indicadores diferem entre si. Portanto, o questionário adaptado foi validado e é confiável. 
Consideradas satisfatórias as relações encontradas na avalição do modelo de mensuração, é possível na segunda fase analisar as relações entre os construtos com avaliação do modelo estrutural. Os critérios compreendem o sinal, a magnitude e o nível de significância dos coeficientes do caminho estrutural, bem como o valor do coeficiente de determinação $R^{2}$. Tomando por base as cargas fatoriais e as relações propostas entre os construtos constata-se que a satisfação com o curso (SAT) obteve um $\mathrm{R}^{2}=0,2267$. Isso significa que a estratégia metacognitiva (MET) e estratégia autorregulatória (AUT), ao formar a estratégia de aprendizagem (APD), são capazes de explicar a variação correspondente a um valor observado em aproximadamente $23 \%$ da satisfação com o curso na modalidade de ensino a distância.

As relações mostraram-se positivas e estatisticamente significantes sobre o teste de efeito total, logo indica-se que as hipóteses H1, H2 e H3 foram suportadas pelo modelo estrutural na análise de caminho estrutural. Sendo assim, a metacognição $($ H1; MET $\rightarrow$ SAT $=$ 0,2878; $\mathrm{p}<0,01)$ e a autorregulação (H2; AUT $\rightarrow$ SAT $=0,2437$; $\mathrm{p}<0,01)$ são positivamente relacionadas com a satisfação com o curso, bem como a estratégia de aprendizagem (H3; $\mathrm{APD} \rightarrow \mathrm{SAT}=0,4761 ; \mathrm{p}<0,01)$ resulta positivamente na satisfação com o curso. A síntese dos resultados é apresentada na Figura 3, nessa as linhas pontilhadas representam o teste de efeito total.

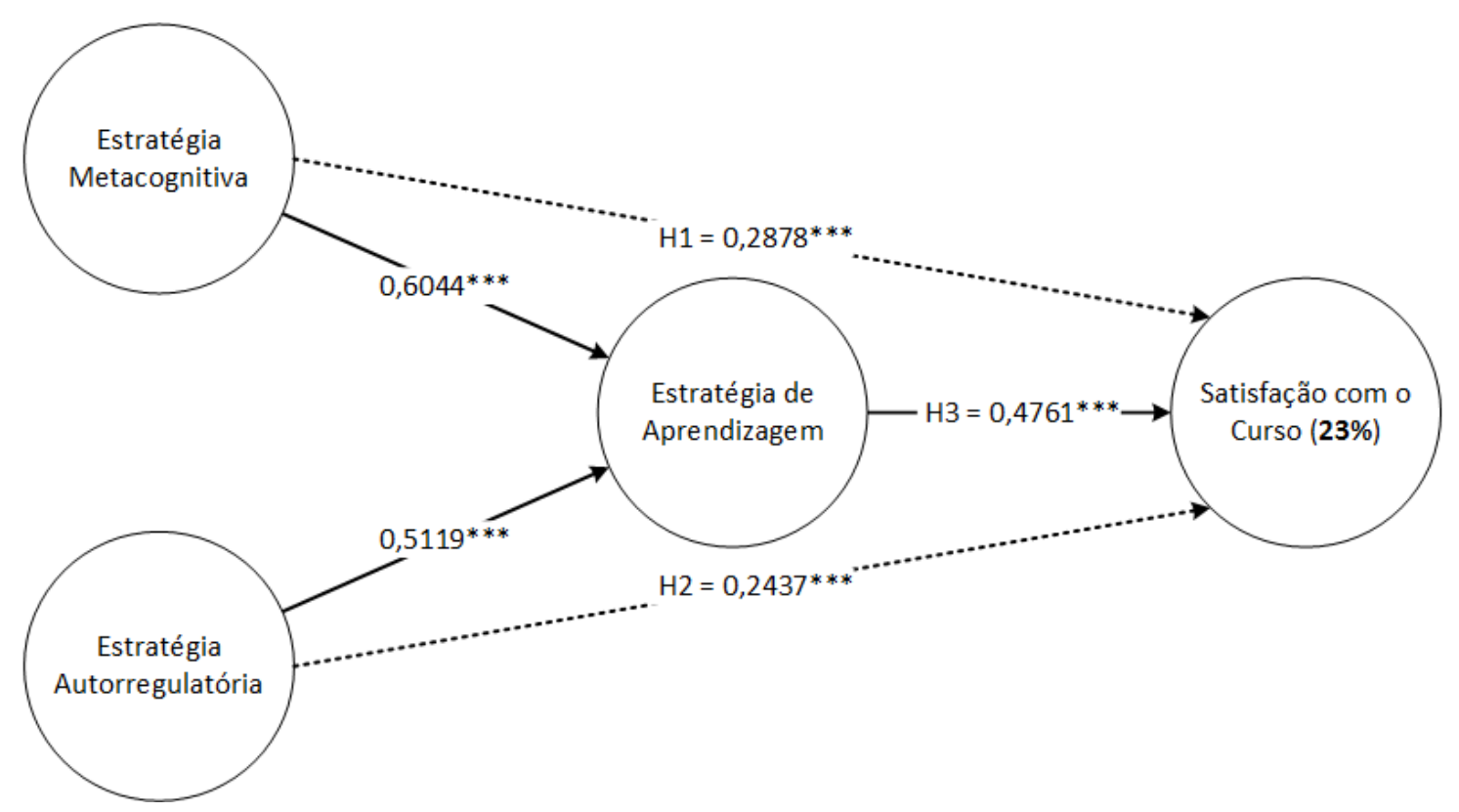

Figura 3 - Síntese dos resultados Nota: $* * * \mathrm{p}<0,01$. Fonte: Dados da pesquisa. 
A PLS-SEM também permite lidar com a heterogeneidade dos dados para entender o comportamento de grupos isolados. A questão que se põe é se as diferenças são estatisticamente significantes. No teste Partial Least Squares Multi-group Analysis (PLSMGA) os valores $\mathrm{p} \leq 0,05$ e $\mathrm{p} \geq 0,95$ indicam diferenças estatisticamente significantes para as estimativas dos grupos (HAIR JR. et al., 2017). A análise comparativa de dois grupos aponta no teste de efeito total que as relações entre AUT $\rightarrow$ SAT, MET $\rightarrow$ SAT e APD $\rightarrow$ SAT são estatisticamente significantes, isto é, as hipóteses da pesquisa. Os resultados são apresentados na Tabela 2.

Tabela 2 - Teste do efeito total na análise multi-grupo

\begin{tabular}{cccc}
\hline Caminho Estrutural & $\begin{array}{c}\text { Diferença Caminho Estrutural } \\
\text { (Egressos - Matriculados) }\end{array}$ & Nível de Significância & p \\
\hline APD $\rightarrow$ SAT & 0,2510 & $* *$ & 0,0045 \\
AUT $\rightarrow$ APD & 0,0332 & NS & 0,7058 \\
AUT $\rightarrow$ SAT & 0,1174 & $* *$ & 0,0181 \\
MET $\rightarrow$ APD & 0,0527 & NS & 0,1824 \\
MET $\rightarrow$ SAT & 0,1724 & $* *$ & 0,0041 \\
\hline
\end{tabular}

Nota: NS $=$ não significante. ${ }^{* *} \mathrm{p}<0,05$. Fonte: Dados da pesquisa.

Existem diferenças e essas são estatisticamente significantes no caminho estrutural entre o grupo de alunos matriculados e o grupo de alunos egressos. Por isso, é possível efetuar a comparação e verificar como ocorrem as diferenças entre o grupo de alunos no que tange a magnitude das relações observadas no caminho estrutural, bem como em relação aos valores do coeficiente de determinação $\mathrm{R}^{2}$ no modelo conceitual. No grupo de alunos matriculados a satisfação com o curso obteve um $\mathrm{R}^{2}=0,0961(\cong 10 \%)$. Os resultados são apresentados na Figura 4, nessa as linhas pontilhadas representam o teste de efeito total. 


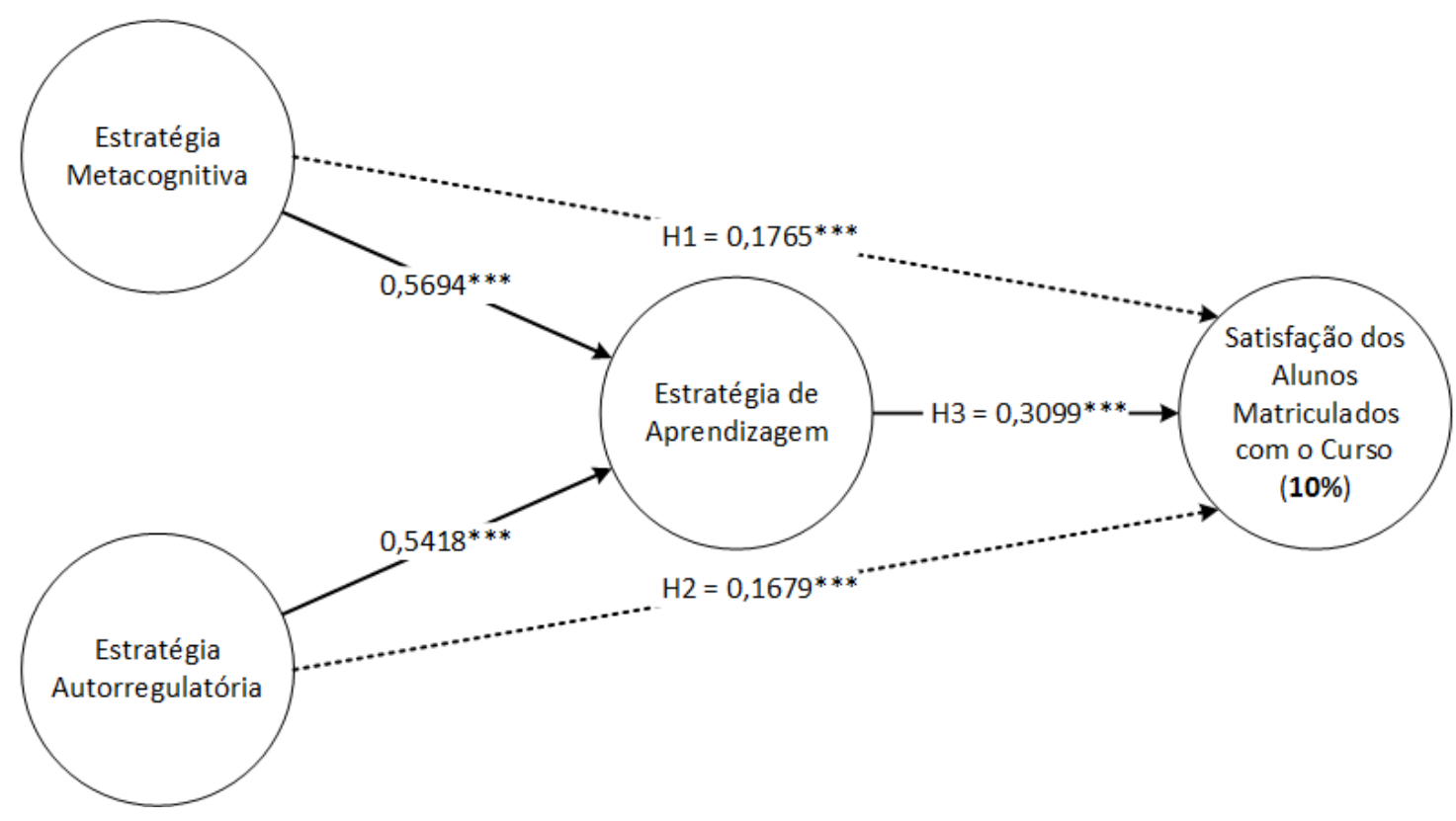

Figura 4 - Resultados do grupo de alunos matriculados Nota: $* * * \mathrm{p}<0,01$. Fonte: Dados da pesquisa.

No grupo de alunos egressos a satisfação com o curso obteve um $\mathrm{R}^{2}=0,3146(\cong 31 \%)$. Os resultados são apresentados na Figura 5, nessa as linhas pontilhadas representam o teste de efeito total.

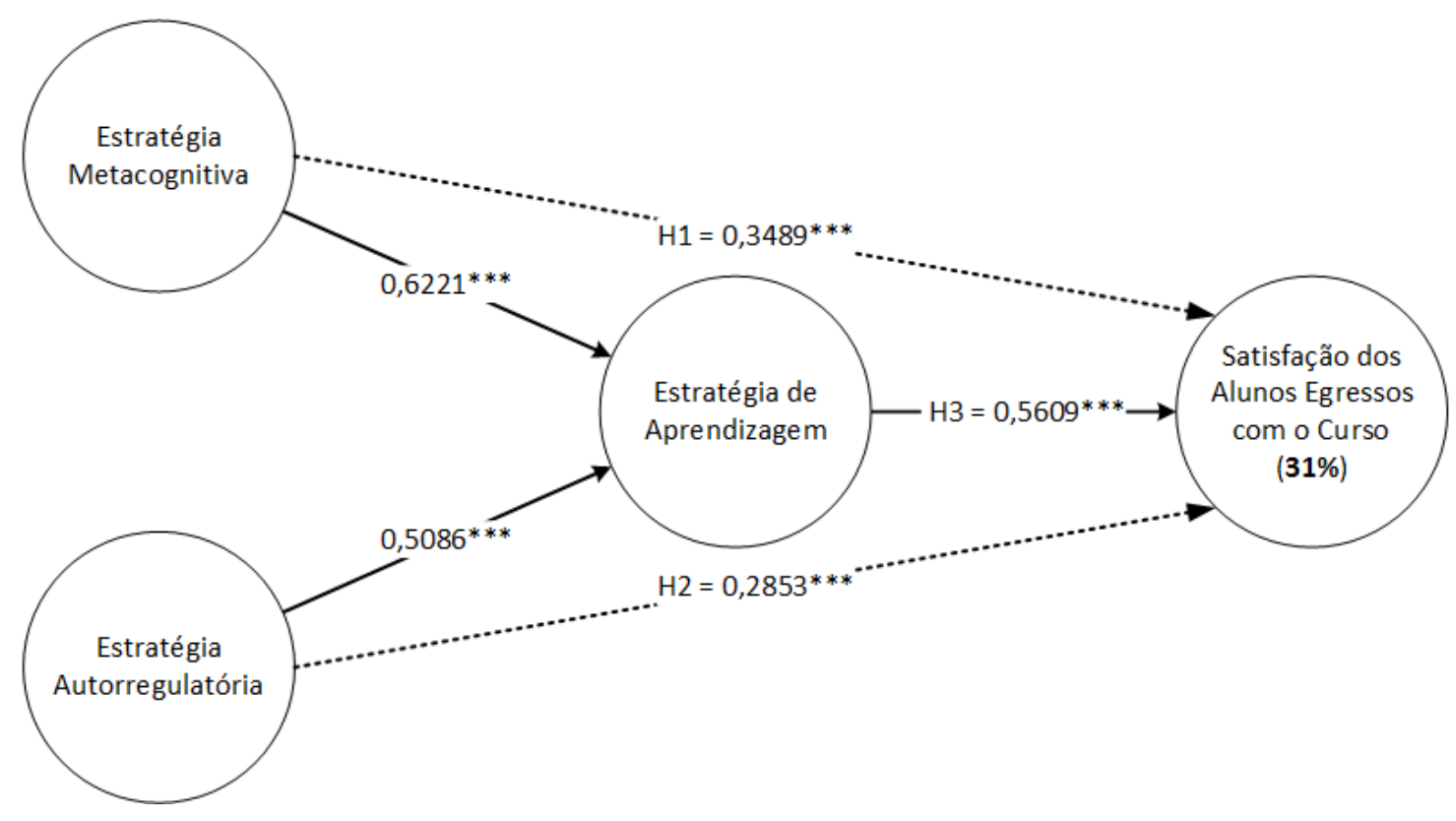

Figura 5 - Resultados do grupo de alunos egressos Nota: $* * * \mathrm{p}<0,01$. Fonte: Dados da pesquisa.

Não se podem fazer inferências no que tange a relação proposta no modelo conceitual entre a estratégia de aprendizagem e seus antecedentes, devido as diferenças entre o grupo de 
alunos nessa relação não ser estatisticamente significante (ver Tabela 2). Todavia, frente a Figura 3 constata-se que a estratégia metacognitiva $(0,6044 ; \mathrm{p}<0,01)$ e a estratégia autorregulatória $(0,5119 ; \mathrm{p}<0,01)$ mostraram-se estatisticamente significantes para formar a estratégia de aprendizagem. Isto significa que o modelo proposto é válido e tem capacidade explicativa em relação a satisfação com o curso demonstrada em cerca de $23 \%$. Em outras palavras, indica que de modo geral os alunos estão realizados com sua trajetória educacional ao confirmar sua expectativa e satisfação com o contexto acadêmico no qual estão inseridos (SOUZA; REINERT, 2010; PACHECO; MESQUITA; DIAS, 2015). Isso comprova que o CEAD/IFMG no Campus Ouro Preto tem cumprido seu papel institucional de educar e qualificar seus alunos para serem cidadãos críticos, criativos, responsáveis e capazes de atuar na transformação da sociedade por meio do exercício profissional em função dos cursos técnicos por eles realizados.

As hipóteses da pesquisa foram suportadas. A estratégia metacognitiva exerce um efeito positivo na satisfação com o curso (H1; 0,2878; p < 0,01). A estratégia autorregulatória exerce um efeito positivo na satisfação com o curso (H2; 0,2437; p < 0,01). A estratégia de aprendizagem tem um efeito positivo na satisfação com o curso $(\mathbf{H 3} ; 0,4761 ; \mathrm{p}<0,01)$. Aponta-se que o crescimento da demanda pela educação profissional e a busca de estratégias para aprender (SCACCHETTI; OLIVEIRA; MOREIRA, 2015) faz com que surjam novas práticas de aprendizagem, mais independentes, autônomas e responsáveis. Essas são essenciais ao bom êxito dos alunos que se matriculam em cursos na modalidade EaD (GÓES; ALLIPRANDINI, 2014). Portanto, é verdadeiro afirmar que a estratégia de aprendizagem, seja ela metacognitiva, que leva o aluno a pensar ou autorregulatória, que estimula o aluno a aprender, quando utilizadas simultaneamente resultam em satisfação com o curso (SOUZA; REINERT, 2010; BARBOSA et al., 2014; SILVA et al., 2015) e por isso, devem ser consideradas pelas IES no que tange a estabelecer políticas que se associam ao processo de aprendizagem, pois ao rever suas práticas de gestão as IES estarão buscando eficiência para possibilitar a consecução de seus objetivos institucionais com foco no ensino (DIAS; SANTOS; BEIRUTH, 2016).

Ao segmentar a amostra em grupo de alunos matriculados, isto é, aquele que está inscrito e registrado e grupo de alunos egressos, isto é, aquele que obteve sucesso na conclusão do curso e tornou-se ex-aluno ao afastar-se do cotidiano educacional (FERREIRA, 2001; CABRAL; SILVA; PACHECO, 2016), identifica-se que a satisfação com o curso corresponde a $10 \%$ para os alunos matriculados e a $31 \%$ para os alunos egressos. Acredita-se 
que a diferença entre os grupos esteja relacionada à inserção deles no mercado de trabalho. Isto porque 50\% dos alunos egressos trabalham na área do curso que realizaram, ao passo que, entre os alunos matriculados, os que trabalham na área do curso representa 39\%, sendo que $43 \%$ nunca trabalharam. Sem sombra de dúvidas conhecer o perfil dos alunos, a valia do curso em relação à trajetória profissional e como isto está representado no mercado de trabalho após o período de formação, representa um indicador para estabelecer políticas de ensino que tenham foco na prática e sejam uteis para os alunos ainda enquanto na condição de matriculados (MURITIBA; ALBUQUERQUE; MOURA, 2012; CABRAL; SILVA; PACHECO, 2016; SANTOS, 2017).

Ao analisar o efeito (ver linha pontilhada da Figura 4 e Figura 5) da estratégia metacognitiva, da estratégia autorregulatória e da estratégia de aprendizagem na satisfação com o curso entre os grupos, observa-se que o grupo de alunos matriculados (Metacognitiva $=$ 0,1765; Autorregulatória $=0,1679 ;$ Aprendizagem $=0,3099 ; \mathrm{p}<0,01)$ apresenta o menor valor quando comparado com o grupo de alunos egressos (Metacognitiva = 0,3489; Autorregulatória $=0,2853$; Aprendizagem $=0,5609 ; \mathrm{p}<0,01$ ). Com esses resultados, sugerese que o aluno que já deixou a escola e trabalha na área para a qual se capacitou consegue perceber com mais clareza a importância da capacitação para sua vida laboral (SCORSOLINI-COMIN, 2013; MARCUZZO et al., 2015). Por isso, considera-se que o aluno egresso que está no mercado de trabalho sente orgulho da qualificação profissional adquirida (MURITIBA; ALBUQUERQUE; MOURA, 2012), enquanto, o aluno que não está inserido no mercado de trabalho, ainda não apresenta condições para perceber a relevância do seu investimento em educação. De qualquer modo, a certeza é que o CEAD/IFMG no Campus Ouro Preto oferta uma educação profissional de qualidade com vistas à atuação dos seus alunos em qualquer um dos setores da economia e isto, contribui para o desenvolvimento socioeconômico local e regional em Minas Gerais.

O aluno se vale da estratégia metacognitiva e da estratégia autorregulatória para consolidar o seu conhecimento (GALVÃO; CÂMARA; JORDÃO, 2013; GÓES; ALLIPRANDINI, 2014; LIMA FILHO; BRUNI, 2015) e assim, destaca-se sob os antecedentes da estratégia de aprendizagem, que a estratégia metacognitiva é aquela que assume o maior valor para ambos grupos. Isto significa que o aluno do curso profissionalizante se vale de processos mentais para realizar uma atividade com sucesso (ZERBINI; ABBAD, 2008). Pensar sobre esses processos e ter controle sobre eles conduz o mesmo para a busca de estratégias que lhe permitam alcançar seus objetivos de aprendizado 
(BARROS; NEVES, 2011; CORSO et al., 2013). Desse modo, quando o aluno toma consciência de que a metacognição é uma ação de reflexão, que ele pode gerenciar, dá à sua aprendizagem um novo direcionamento e usa essa habilidade para desenvolver mudanças cognitivas em sua rotina de estudos (ZERBINI; ABBAD, 2008; BARROS; NEVES, 2011; GALVÃO; CÂMARA; JORDÃO, 2013), de forma que a pesquisa aplicada, a inovação tecnológica, o desenvolvimento científico, o cooperativismo, o empreendedorismo e a produção cultural são alguns exemplos de atividades acadêmicas que os alunos executam no processo de apreender para integrar-se à sociedade.

\section{CONSIDERAÇÕES FINAIS}

Este estudo analisou as relações das estratégias de aprendizagem na satisfação com o curso na modalidade de educação profissional a distância em função dos alunos matriculados e egressos do CEAD/IFMG, em específico, no nível técnico. Os resultados apontam que o modelo proposto teve a capacidade de explicar $23 \%$ da satisfação com o curso, sendo que por grupo de alunos, implica em uma satisfação com o curso de $10 \%$ para os alunos matriculados e 31\% para os alunos egressos. Sendo assim, a indicação é que aquele aluno que já deixou a instituição e atua profissionalmente na área para a qual se capacitou consegue perceber com mais clareza a importância da capacitação para sua vida profissional, logo, demonstra uma maior satisfação com o curso técnico, enquanto que aquele aluno que ainda não está inserido no mercado de trabalho não apresenta tanta clareza na questão da satisfação com seu curso profissional.

A pesquisa contribui para a discussão acerca das estratégias de aprendizagem relacionadas à satisfação com os cursos da modalidade EaD de cunho profissional, posto que o estudo analisou a percepção dos alunos quanto à relevância do curso e à qualidade de sua qualificação profissional, as quais, estão sobre à satisfação obtida com a conclusão do curso para os alunos egressos, ou mesmo, para a perspectiva de satisfação identificada para os alunos matriculados. O pragmatismo que recai sobre a pesquisa está no fato de que o modelo conceitual apresentado pode ser utilizado como uma ferramenta de gestão pelas IES para elencar, avaliar, analisar e validar a qualidade dos cursos ofertados na ótica dos alunos, bem como as relações existentes entre as estratégias de aprendizagem adotadas pelos alunos e como essas incidem na satisfação com o curso, em outras palavras, um possível 
potencializador para estabelecer políticas públicas que tenham o objetivo de evoluir a qualidade dos cursos da educação superior.

A principal limitação está no fato de que os alunos matriculados representaram o menor tamanho da amostra, quando essa foi segmentada por grupo de alunos. Isso decorre do fato de que o questionário foi aplicado por ocasião do encontro presencial dos cursos, entretanto, com a ausência de alguns alunos não foi possível realizar uma maior aquisição de informações com esses respondentes. Como sugestão para pesquisas futuras, acredita-se que o modelo possa ser utilizado por outras IES, sejam elas públicas ou privadas, atuando em qualquer nível de educação, pois a replicação da pesquisa pode ajudar a compreender como se dá a relação entre seus alunos e a satisfação com o curso. O modelo também pode evoluir, por exemplo, ao considerar o desempenho profissional dos alunos como consequente da satisfação com o curso.

A forma com que se aprende, bem como se aprende a aprender, diz respeito ao ganho contínuo de capacitação e competência, o que se torna mister no sucesso do profissional e das organizações, por isso, a verificação é que o conhecimento das estratégias de aprendizagem, por parte da gestão educacional, poderá permitir ao Campus Ouro Preto do IFMG elaborar planos de ação que sejam apresentados aos alunos. Essa possibilidade corrobora as análises de Chaves et al., (2014) e, Arosti e Dumbra (2014), quando eles argumentam sobre o papel dos docentes e dos demais profissionais que atuam na modalidade $\mathrm{EaD}$, como os tutores ou técnicos educacionais, com o intuito de que os alunos façam cada vez mais uso da estratégia metacognitiva e estratégia autorregulatória em benefício de sua aprendizagem e consequentemente, sintam-se satisfeitos com o curso no qual se matricularam.

\title{
LEARNING STRATEGIES AND DISTANCE EDUCATION COURSES: SATISFACTION OF STUDENTS ENROLLED AND GRADUATED IN PROFESSIONAL COURSES
}

\begin{abstract}
The higher education institutions need to understand the perceptions of their students to effectively establish academic management actions. This study exhibits the effect of the learning strategies on course satisfaction of the enrolled and graduated students from Open and Distance Education Center of Ouro Preto Campus of the Federal Institute of Minas Gerais in Brazil. Metacognitive strategy and self-regulatory strategy are the antecedents of the learning strategies. Data analysis used multivariate statistics through Partial Least Squares Structural Equation Modeling. The results point out that the students who entered the labor market in the field of knowledge of the course they performed clearly perceive the importance
\end{abstract}


of training and education in their professional life. Metacognitive strategy is the one that stands out, because it is the one that leads the student to reflect on his own thinking to carry out a successful activity and achieve his learning objective.

Keywords: Education. Metacognition. Self-regulation. Multi-group analysis. PLS-MGA.

\section{REFERÊNCIAS}

ABBAD, Gardênia da Silva; CORRÊA, Vinícius Pinto; MENESES, Pedro Paulo Murce. Avaliação de treinamentos a distância: Relações entre estratégias de aprendizagem e satisfação com o treinamento. Revista de Administração Mackenzie, São Paulo, v. 11, n. 2, p. 43-67, 2010. doi: http://dx.doi.org/10.1590/s1678-69712010000200003.

AFFONSO, Suselei Bedin; QUINELATO, Eliane. Educação a distância: algumas considerações a respeito do autogerenciamento da aprendizagem pelos estudantes. Revista Científica em Educação a Distância, Santos, v. 4, n. 2, p. 77-87, 2014. doi: http://dx.doi.org/10.18264/eadf.v4i2.200.

ALLIPRANDINI, Paula Mariza Zedu; SCHIAVONI, Andreza; MELL, Diene Eire de; SEKITANI, Juliane Tiene. Estratégias de aprendizagem utilizadas por estudantes na educação a distância: implicações educacionais. Psicologia da Educação, São Paulo, v. 38, n. 1, p. 5$16,2014$.

AROSTI, Danilo; DUMBRA, Soraia. Origens e desafios da gestão da educação a distância: O papel do gestor dentro de um novo ambiente educacional. Revista Científica Eletrônica Estácio, Ribeirão Preto, v. 4, n. 1, p. 169-180, 2014.

BARBOZA, Souza Stephanie Ingrid; CARVALHO, Diana Lúcia Teixeira de; SOARES NETO, João Batista; DA COSTA, Francisco José. Uma análise dos condicionantes da satisfação, da dedicação e do desempenho de estudantes de cursos de administração. Administração, Ensino e Pesquisa, Rio de Janeiro, v. 15, n. 2, p. 323-349, 2014. doi: http://dx.doi.org/10.13058/raep.2014.v15n2.23.

BARROS, Dirlene Santos; NEVES, Dulce Amélia de Brito. Estudo de usuários no arquivo público do estado do Maranhão (APEM): analisando as estratégias metacognitivas no processo de busca de informação. Perspectivas em Ciência da Informação, Belo Horizonte, v. 16, n. 4, p. 228-242, 2011. doi: http://dx.doi.org/10.1590/s1413-99362011000400014.

BORUCHOVITCH, Evely. Estratégias de aprendizagem e desempenho escolar: Considerações para a prática educacional. Psicologia, Reflexão e Crítica, Porto Alegre, v. 12, n. 2, p. 1-15, 1999. doi: http://dx.doi.org/10.1590/s0102-79721999000200008.

CABRAL, Thiago Luiz de Oliveira; SILVA, Fernanda Cristina da; PACHECO, Andressa Sasaki Vasques. As universidades e o relacionamento com seus ex-alunos: uma análise de portais online de egressos. Revista Gestão Universitária na América Latina, Florianópolis, v. 9, n. 3, p. 157-173, 2016. doi: http://dx.doi.org/10.5007/1983-4535.2016v9n3p157. 
CASTRO, Juliana Xavier; MIRANDA, Gilberto José; LEAL, Edvalda Araújo. Estratégias de aprendizagem dos estudantes motivados. Advances in Scientific and Applied Accounting, v. 9, n. 1, p. 80-97, 2016. doi: http://dx.doi.org/10.14392/asaa.2016090105.

CHAVES, Vera Lúcia Jacob; GUTIERRES, Dalva Valente Guimarães; MENDES, Odete da Cruz; RIBEIRO, Maria Edilene da Silva. Gestão da educação: Uma revisão conceitual na perspectiva de análise do plano de ações articuladas. In: CONGRESSO IBEROAMERICANO DE POLÍTICA E ADMINISTRAÇÃO DA EDUCAÇÃO, 4., 2014, Porto, Portugal. Anais [...] Goiânia: ANPAE, 2014. 1-15 p.

COHEN, Jacob. A power primer. Psychological Bulletin, v. 112, n. 1, p. 155-159, 1992. doi: http://dx.doi.org/10.1037/0033-2909.112.1.155.

CORSO, Helena Velhinho; SPERB, Tânia Mara; JOU, Graciela Inchausti de; SALLES, Jerusa Fumagalli. Metacognição e funções executivas: relações entre os conceitos e implicações para a aprendizagem. Psicologia, Teoria e Pesquisa, Brasília, v. 29, n. 1, p. 21 29, 2013. doi: http://dx.doi.org/10.1590/s0102-37722013000100004.

CROTI, Adriana Aparecida. Aprender a aprender: A autorregulação na perspectiva cognitiva da aprendizagem no contexto do ensino profissionalizante. 2016. 157 f. Dissertação (Mestrado em Educação) - Universidade do Oeste Paulista, Presidente Prudente, 2016.

DANTAS, Cláudia; RODRIGUES, Camila Cruz. Estratégias metacognitivas como intervenção psicopedagógica para o desenvolvimento do automonitoramento. Revista Psicopedagogia, São Paulo, v. 30, n. 93, p. 226-235, 2013.

DIAS, Alexsandra Barcelos; SANTOS, Valquíria Aparecida dos; BEIRUTH, Aziz Xavier. Consistência das estratégias de instituições de ensino superior: um estudo baseado na percepção dos stakeholders utilizando-se do Balanced Scorecard. Revista de Educação e Pesquisa em Contabilidade, Brasília, v. 10, n. 4, p. 431-448, 2016. doi: http://dx.doi.org/10.17524/repec.v10i4.1445.

FALCIONI, Roberto Evair; AMORIM, Mário Lopes. O ensino profissionalizante na sociedade moderna industrial: um olhar histórico. Revista Tecnologia e Sociedade, Curitiba, v. 5, n. 8, p. 1-13, 2009. doi: http://dx.doi.org/10.3895/rts.v5n8.2530.

FARIAS, Adriano Antônio; LOPES, Luis Fernando. Práticas pedagógicas em EaD. Curitiba: Intersaberes, 2014.

FAUL, Franz; BUCHNER, Axel; ERDFELDER, Edgar; LANG, Albert-Georg. Statistical power analyses using $\mathrm{G}^{*}$ Power 3.1: tests for correlation and regression analyses. Behavior Research Methods, v. 41, n. 4, p. 1149-1160, 2009. doi: http://dx.doi.org/10.3758/brm.41.4.1149.

FERNANDES, Verônica Rodriguez; FRISON, Lourdes Maria Bragagnolo. Estratégias de aprendizagem autorregulatória no ensino superior: Escrita de um artigo científico. Psicologia da Educação, São Paulo, v. 41, n. 1, p. 37-49, 2015. doi: http://dx.doi.org/10.5935/2175$\underline{3520.20150013 .}$. 
FERREIRA, Aurélio Buarque de Holanda. Miniaurélio século XXI escolar: o minidicionário da língua Portuguesa. 4. ed. Rio de Janeiro: Nova Fronteira, 2001.

FORTES, Renata Costa; HAACK, Adriana. Atitudes de alunos e de professores com relação à adoção da modalidade de educação a distância. Revista de Divulgação Científica Sena Aires, Chácaras Anhaguera Valparaiso de Goiás, v. 2, n. 1, p. 73-87, 2013.

GALVÃO, Afonso; CÂMARA, Jacira; JORDÃO, Michelle. Estratégias de aprendizagem: reflexões sobre universitários. Revista Brasileira de Estudos Pedagógicos, Brasília, v. 93, n. 235, p. 627-644, 2013. doi: http://dx.doi.org/10.1590/s2176-66812012000400006.

GÓES, Natália Moraes; ALLIPRANDINI, Paula Mariza Zedu. Análise das estratégias de aprendizagem cognitivas, autorregulatórias e comportamentais utilizadas por alunos de um curso de pedagogia ofertado a distância. In: ASSOCIAÇÃO NACIONAL DE PÓSGRADUAÇÃO E PESQUISA EM EDUCAÇÃO, 10., 2014, Florianópolis. Anais... Rio de Janeiro: ANPED, 2014. 1-20 p.

GÓES, Natália Moraes; PAVESI, Marilza Aparecida; ALLIPRANDINI, Paula Mariza Zedu. Estratégias de aprendizagem utilizadas por alunos do curso de pedagogia de uma IES pública do estado do Paraná ofertado a distância. Novas Tecnologias na Educação, Porto Alegre, v. 11, n. 3, p. 1-10, 2013.

GOUVÊA, M. A.; ONUSIC, L. M.; MANTOVANI, D. M. N. Qualidade e lealdade ao curso no ensino superior. Revista de Administração da UFSM, Santa Maria, v. 9, n. 1, p. 26-45, 2016. doi: http://dx.doi.org/10.5902/198346597690.

HAIR JR, Joseph F.; HULT, G. Tomas M.; RINGLE, Christian; SARSTEDT, Marko. A primer on partial least squares structural equation modeling (PLS-SEM). 2. ed. Thousand Oaks: Sage, 2017.

HAIR JR, Joseph F.; RINGLE, Christian M.; SARSTEDT, Marko. PLS-SEM: indeed a silver bullet. Journal of Marketing Theory and Practice, v. 19, n. 2, p. 139-151, 2011. doi: http://dx.doi.org/10.2753/mtp1069-6679190202.

ISLER, Gustavo Lima; MACHADO, Afonso Antonio. Motivação discente em cursos na modalidade de educação a distância (EaD): fatores que influenciam. Revista Nupem, Campo Mourão, v. 5, n. 9, p. 67-84, 2013.

$\mathrm{KOCH}$, Simone Hack da Silva. Aprender a aprender: na busca de processos metacognitivos com o uso das TIC. 2011. 177 f. Dissertação (Mestrado em Educação) - Universidade Federal do Rio Grande do Sul, Porto Alegre, 2011

LIMA FILHO, Raimundo Nonato; BRUNI, Adriano Leal. Metacognição estimula características empreendedoras? Uma análise em profissionais de administração. Revista de Administração, Contabilidade e Economia, Joaçaba, v. 14, n. 2, p. 427-450, 2015. doi: http://dx.doi.org/10.18593/race.v14i2.5922.

LOHMÖLLER, Jan-Bernd. The PLS program system: latent variables path analysis with partial least squares estimation. Multivariate Behavioral Research, v. 23, n. 1, p. 125-127, 1988. doi: http://dx.doi.org/10.1207/s15327906mbr2301_7. 
MAINARDES, Emerson Wagner; DOMINGUES, Maria José Carvalho de Souza. Lealdade de estudantes em instituições de ensino superior: um estudo multicaso em Joinville. Revista Eletrônica de Gestão de Negócios, São Paulo, v. 6, n. 3, p. 1-30, 2010.

MARCUZZO, Marlei Maria Veduim; GUBIANI, Juçara Salete; LOPES, Luis Felipe Dias; REGIO, Maria de Lourdes Severo. A satisfação dos alunos de educação a distância: Um estudo de caso aplicado em nível de graduação e pós-graduação de uma universidade federal. In: COLÓQUIO INTERNACIONAL DE GESTÃO UNIVERSITÁRIA, 15., 2015, Mar del Plata, Argentina. Anais [...]. Florianópolis: UFSC, 2015. 1-16 p.

MIRANDA, Fabio Neves de; TONINI, Adriana Maria. Estratégias pedagógicas de ensinoaprendizagem nos cursos técnicos do CEFET-MG na modalidade a distância. In: SEMINÁRIO INTERNACIONAL DE EDUCAÇÃO A DISTÂNCIA, 5., 2013, Belo Horizonte. Anais [...]. Belo Horizonte: UFMG, 2013.

MURITIBA, Patricia Morilha; MURITIBA, Sérgio Nunes; ALBUQUERQUE, Lindolfo Galvão de; MOURA, Maurício Serpa Barros de. Satisfação dos egressos em administração, economia e contabilidade e desempenho profissional. Revista Alcance, Biguaçu, v. 19, n. 3, p. 308-326, 2012. doi: http://dx.doi.org/10.14210/alcance.v19n3.p308-326.

OLIVEIRA, Katya Luciane de; BORUCHOVITCH, Evely; SANTOS, Acácia Aparecida Angeli dos. Estratégias de aprendizagem e desempenho acadêmico: evidências de validade. Psicologia, Teoria e Pesquisa, Brasília, v. 25, n. 4, p. 531-536, 2009. doi: http://dx.doi.org/10.1590/s0102-37722009000400008.

OLIVEIRA, Ronielton Rezende; GONÇALVES, Carlos Alberto; MARTINS, Henrique Cordeiro. Desempenho organizacional: integração do modelo valor, raridade, imitabilidade e organização com a gestão de projetos. Contabilidade, Gestão e Governança, Brasília, v. 20, n. 2, p. 252-275, 2017. doi: http://dx.doi.org/10.21714/1984-3925_2017v20n2a5.

OLIVEIRA, Ronielton Rezende; MARINHO, Marlon Finelli Avendanha; DIAS, Alexandre Teixeira. Um estudo sobre a utilização da modelagem de equações estruturais na produção científica nas áreas de administração e sistemas de informação. Revista de Administração da UFSM, Santa Maria, v. 9, n. 4, p. 559-578, 2016. doi:

http://dx.doi.org/10.5902/198346598610.

OLIVER, R. L. A cognitive model of the antecedents and consequences of satisfaction decisions. Journal of Marketing Research, v. 17, n. 4, p. 460-469, 1980. doi: http://dx.doi.org/10.2307/3150499.

PACHECO, Iram José Duarte; MESQUITA, José Marcos Carvalho de; DIAS, Alexandre Teixeira. Qualidade percebida e satisfação dos alunos da rede federal de educação profissional e tecnológica. Revista Gestão \& Tecnologia, Pedro Leopoldo, v. 15, n. 2, p. 5-28, 2015. doi: http://dx.doi.org/10.20397/2177-6652/2015.v15i2.831.

PAULINO, Paula; SILVA, Adelina Lopes da. Promover a regulação da motivação na aprendizagem. Cadernos de Educação, Pelotas, v. 42, n. 1, p. 96-118, 2012. 
PERASSINOTO, Maria Gislaine Marques; BORUCHOVITCH, Evely; BZUNECK, José Aloyseo. Estratégias de aprendizagem e motivação para aprender de alunos do ensino fundamental. Avaliação Psicológica, Campinas, v. 12, n. 3, p. 351-359, 2013.

RAMOS, Aline Marcelino; BARLEM, Jamila Geri Tomaschewski; LUNARDI, Valéria Lerch; BARLEM, Edison Luiz Devos; SILVEIRA, Rosemary Silva da; BORDIGNON, Simoní Saraiva. Satisfação com a experiência acadêmica entre estudantes de graduação em enfermagem. Texto Contexto Enfermagem, Florianópolis, v. 24, n. 1, p. 187-195, 2015. doi: http://dx.doi.org/10.1590/0104-07072015002870013.

RINGLE, Christian M.; WENDE, Sven; BECKER, Jan-Michael SmartPLS 3. Bönningstedt: SmartPLS GmbH, 2015. Disponivel em: http://www.smartpls.com.

SALOVAARA, Hanna. An exploration of students' strategy use in inquiry-based computersupported collaborative learning. Journal of Computer Assisted Learning, v. 21, n. 1, p. 3952, 2005. doi: http://dx.doi.org/10.1111/j.1365-2729.2005.00112.x.

SANTOS, Adilson Gomes; CARDOSO, Ariston Lima; BORGES, Luzineide Miranda Educação a distância: motivações, expectativas e aprendizagem. In: CONGRESSO BRASILEIRO DE ENSINO SUPERIOR A DISTÂNCIA, 11., 2014, Florianópolis. Anais [...]. Florianópolis: UFSC, 2014. 2059-2072 p.

SANTOS, Maria Edilene do Amaral Silva. Educação a distância: relações entre as estratégias de aprendizagem e a satisfação de alunos. 2017. 82 f. Dissertação (Mestrado em Administração) - Universidade FUMEC, Belo Horizonte, 2017.

SCACCHETTI, Fabio Alexandre Pereira; OLIVEIRA, Katya Luciane de; MOREIRA, Ana Elisa da Costa. Estratégias de aprendizagem no ensino técnico profissional. Psico-USF, Campinas, v. 30, n. 3, p. 433-446, 2015. doi: http://dx.doi.org/10.1590/1413$\underline{82712015200306 .}$.

SCACCHETTI, Fabio Alexandre Pereira; OLIVEIRA, Katya Luciane de; RUFINI, Sueli Édi. Medida de motivação para aprendizagem no ensino técnico profissional. Avaliação Psicológica, Campinas, v. 13, n. 2, p. 297-305, 2014.

SCORSOLINI-COMIN, Fabio. Psicologia do desenvolvimento, educação a distância e as tecnologias digitais da informação e da comunicação. Psico, Porto Alegre, v. 44, n. 3, p. 352$361,2013$.

SEVERINI, Edson Roberto; ORELLANO, Verônica Inês Fernandez. O efeito do ensino profissionalizante sobre a probabilidade de inserção no mercado de trabalho. Revista Economia, Belo Horizonte, v. 11, n. 1, p. 155-174, 2010.

SILVA, Denise Mendes da; LEAL, Edvalda Araujo; PEREIRA, Janser Moura; OLIVEIRA NETO, José Dutra de. Estilos de aprendizagem e desempenho acadêmico na educação a distância: Uma investigação em cursos de especialização. Revista Brasileira de Gestão de Negócios, São Paulo, v. 17, n. 57, p. 1300-1316, 2015. doi: http://dx.doi.org/10.7819/rbgn.v17i57.1852. 
SOARES, Maria Susana Arrosa (Org.). A educação superior no Brasil. Porto Alegre: IESALC, 2002. Disponivel em: http://goo.gl/XD2VhL. Acesso em: 15 de julho de 2017.

SOUZA, Saulo Aparecido de; REINERT, José Nilson. Avaliação de um curso de ensino superior através da satisfação/insatisfação discente. Revista da Avaliação da Educação Superior, Sorocaba, v. 15, n. 1, p. 159-176, 2010. doi: http://dx.doi.org/10.1590/s141440772010000100009.

UMEKAWA, Elienay Eiko Rodrigues; ZERBINI, Thaís. Evasão e persistência em ações educacionais a distância: análise do perfil discente. Revista Psicologia, Organizações e Trabalho, Florianópolis, v. 15, n. 2, p. 188-200, 2015. doi: http://dx.doi.org/10.17652/rpot/2015.2.517.

VALE, Aline Francilurdes Nery do; OLIVEIRA, Agostinha Mafalda Barra de; SOUSA, Juliana Carvalho de. Grau de satisfação dos discentes de administração com seu curso e sua IES. Revista de Administração IMED, Passo Fundo, v. 6, n. 1, p. 105-115, 2016. doi: http://dx.doi.org/10.18256/2237-7956/raimed.v6n1p105-115.

VIEIRA, Kelmara Mendes; MILACH, Felipe Tavares; HUPPES, Daniela. Equações estruturais aplicadas à satisfação dos alunos: um estudo no curso de ciências contábeis da Universidade Federal de Santa Maria. Revista Contabilidade Financeira, São Paulo, v. 19, n. 48, p. 65-76, 2008. doi: http://dx.doi.org/10.1590/s1519-70772008000300006.

WARR, Peter; ALLAN, Catriona. Learning strategies and occupational training. In: COOPER, Cary L.; ROBERTSON, Ivan T. Internacional Review of Industrial and Organizational Psychology, New York, v. 13, 1998. p. 83-122.

ZERBINI, Thaís; ABBAD, Gardênia Estratégias de aprendizagem em curso a distância: validação de uma escala. Psico-USF, Campinas, v. 13, n. 2, p. 177-187, 2008. doi: http://dx.doi.org/10.1590/s1413-82712008000200005.

\section{DADOS DOS AUTORES}

\section{Ronielton Rezende Oliveira}

E-mail: ronielton@fumec.edu.br

Currículo Lattes: http://lattes.cnpq.br/9615908397053311

Doutorando em Sistemas de Informação e Gestão do Conhecimento pela Universidade Fundação Mineira de Educação e Cultura (FUMEC) com período sanduíche planejado para a Universidade de Coimbra/Portugal, doutor em Administração e mestre em Sistemas de Informação e Gestão do Conhecimento pela FUMEC, MBA Executivo Internacional pela Ohio State University/United States (OSU), MBA Gerenciamento de Projetos pela Fundação Getulio Vargas (FGV), Especialização em Criptografia e Segurança em Redes pela Universidade Federal Fluminense (UFF) e Graduação em Ciência da Computação pela Universidade Vale do Rio Verde (UninCor)

\section{Luiz Antônio Antunes Teixeira}

E-mail: lantonio@fumec.br

Currículo Lattes: http://lattes.cnpq.br/5866500472830974 
Doutor em Direção de Empresas pelo Instituto de Estúdios Superiores de La Empresa, graduação em Filosofia pela Universidade Federal de Minas Gerais. Atualmente é professor titular da Universidade FUMEC. Tem experiência na área de Administração, com ênfase em Administração, atuando principalmente nos seguintes temas: administração, gestão, marketing, turismo sustentável e competitividade.

\section{Maria Edilene do Amaral Silva Santos}

E-mail: edilene.amaral@ifmg.edu.br

Currículo Lattes: http://lattes.cnpq.br/1747454160548000

Mestre em Administração pela FUMEC, graduação em Pedagogia pela Faculdade de Filosofia, Ciências e Letras de Varginha (FAFI). Atualmente é Técnica em Assuntos Educacionais - TAE do Instituto Federal Minas Gerais IFMG - Campus Ouro Preto, atuando no Controle Acadêmico do Centro de Educação Aberta e a Distância (CEAD). 